\title{
Role of Preferential Ions of Ammonium Ionic Liquid in
}

\section{Destabilization of Collagen}

Aafiya Tarannum, Charuvaka Muvva, Ami Mehta, J. Raghava Rao, N. Nishad Fathima*

Chemical Laboratory, CSIR-Central Leather Research Institute, Adyar, Chennai 600020, India

*Corresponding Author

Chemical Laboratory, CSIR-Central Leather Research Institute

Adyar, Chennai 600020, India

Tel.: +91 44 24437188; fax: +91 4424911589

E-mail addresses: nishad@clri.res.in, nishad.naveed@gmail.com (N. N. Fathima) 
3.1 Supporting Information for Viscosity studies

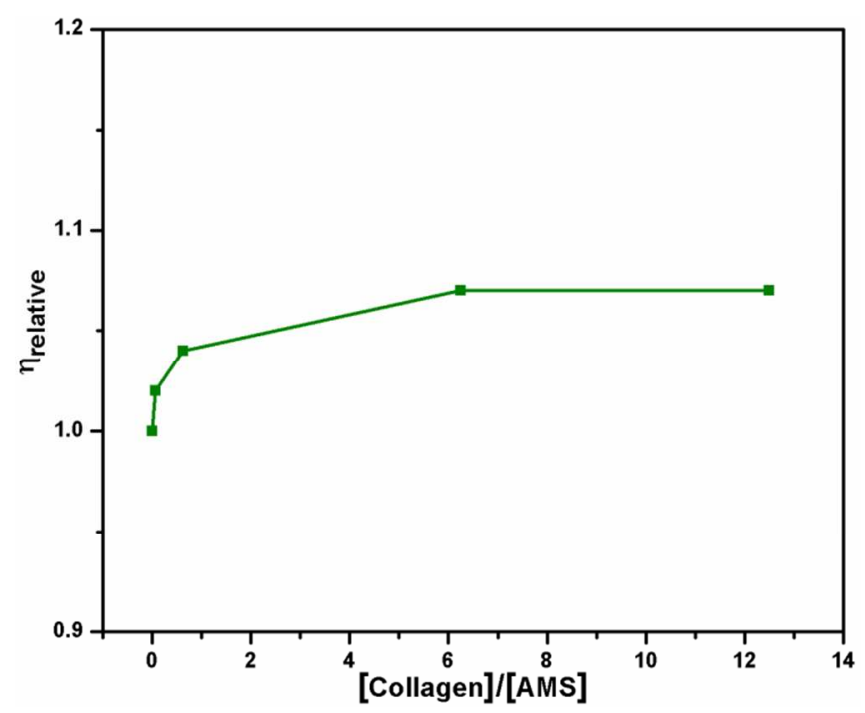

Figure S1. Plot of relative viscosity against $1 / R, R=[$ Collagen $] /[A M S]$ (Temperature: $\left.25^{\circ} \mathrm{C}\right)$, Collagen: Ammonium methane sulfonate, C-AMS-1 to C-AMS-4 (1:0.05\% to $1: 10 \%)$ 
3.2 Supporting Information for UV-Vis spectroscopic studies

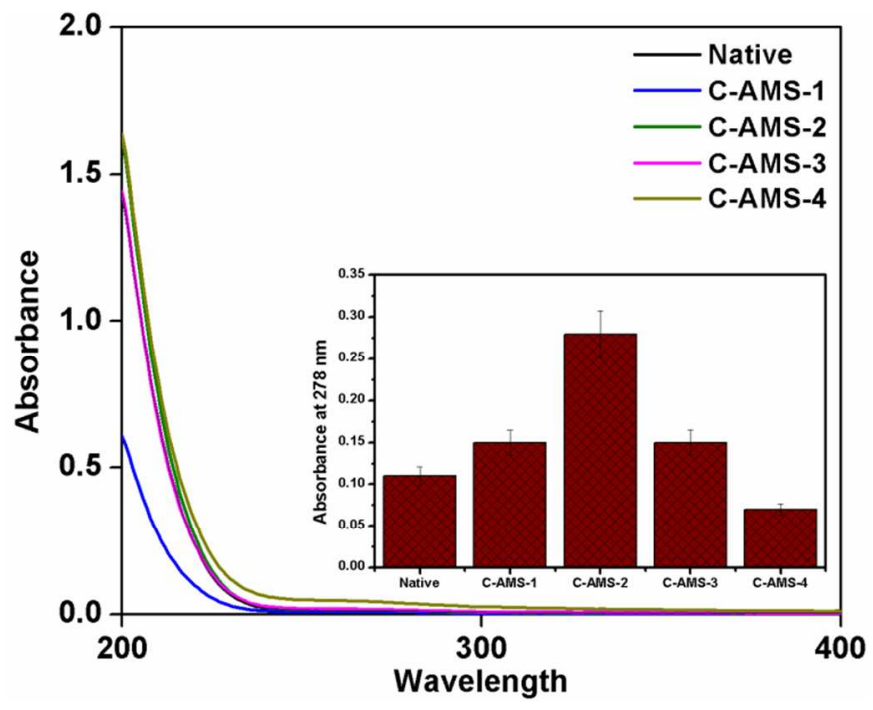

Figure S2. UV - Vis spectra for native and ammonium methane sulfonate (AMS) treated collagen (Absorbance at $278 \mathrm{~nm}$ for different molar ratios in the inset) Collagen: Ammonium methane sulfonate, C-AMS-1 to C-AMS-4 (1:0.05\% to 1:10\%) 


\subsection{Supporting Information for CD spectral studies}
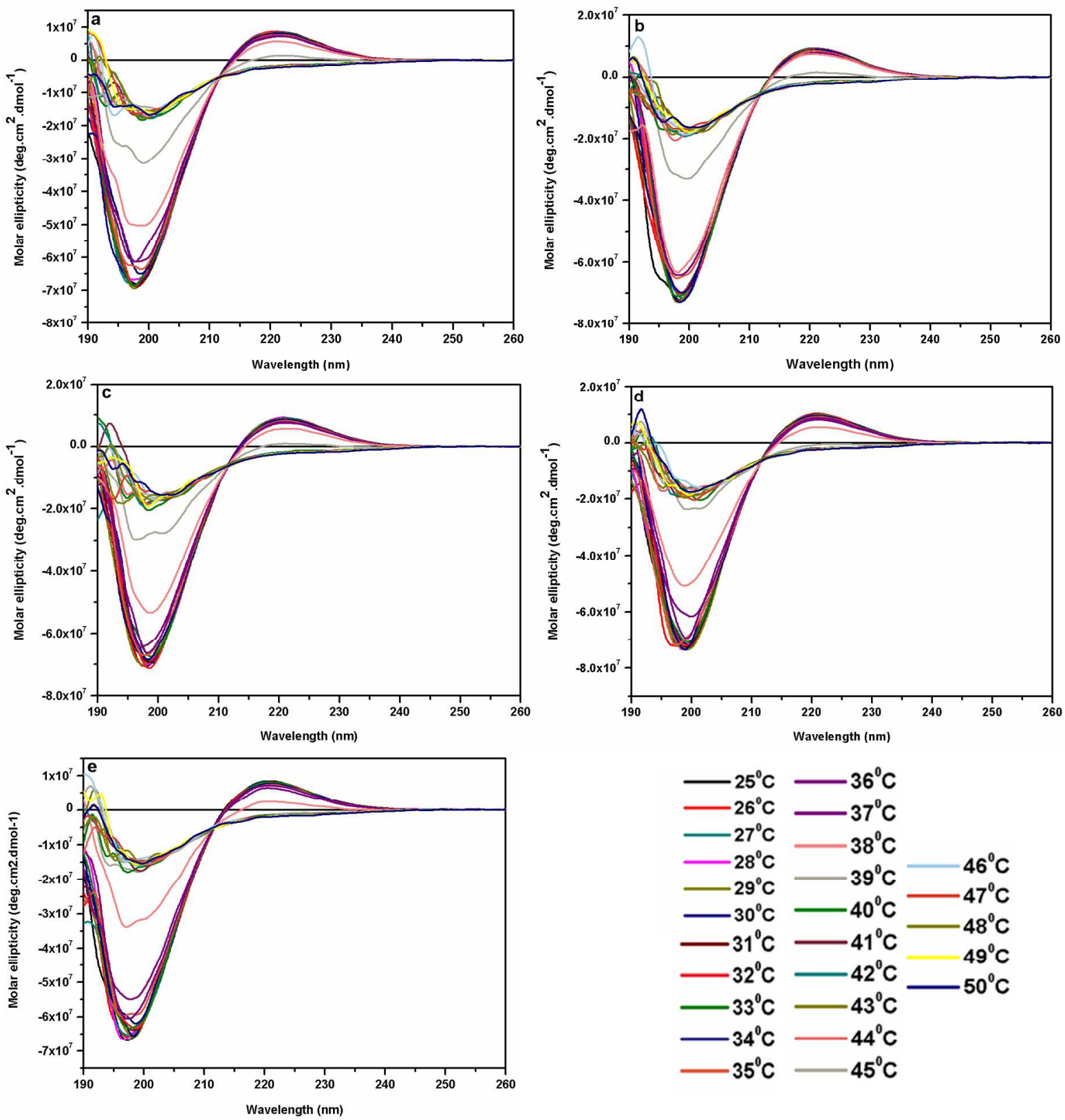

S3. Temperature dependent circular dichroic spectroscopic measurement from $25^{\circ} \mathrm{C}$ to ${ }_{50}{ }^{\circ} \mathrm{C}$ for a) native collagen, b) C-AMS-1 (0.05\%), c) C-AMS-2 (0.5\%), d) C-AMS-3 (5\%) and e) C-AMS-4 (10\%) 